AperTO - Archivio Istituzionale Open Access dell'Università di Torino

Genetic and phenotypic characterisation of Escherichia coli producing cefotaximase-type extended-spectrum $\beta$-lactamases: first evidence of the ST131 clone in cats with urinary infections in Italy.

This is the author's manuscript

Original Citation:

Availability:

This version is available http://hdl.handle.net/2318/149735

since

Published version:

DOI:10.1177/1098612X14527103

Terms of use:

Open Access

Anyone can freely access the full text of works made available as "Open Access". Works made available under a Creative Commons license can be used according to the terms and conditions of said license. Use of all other works requires consent of the right holder (author or publisher) if not exempted from copyright protection by the applicable law. 


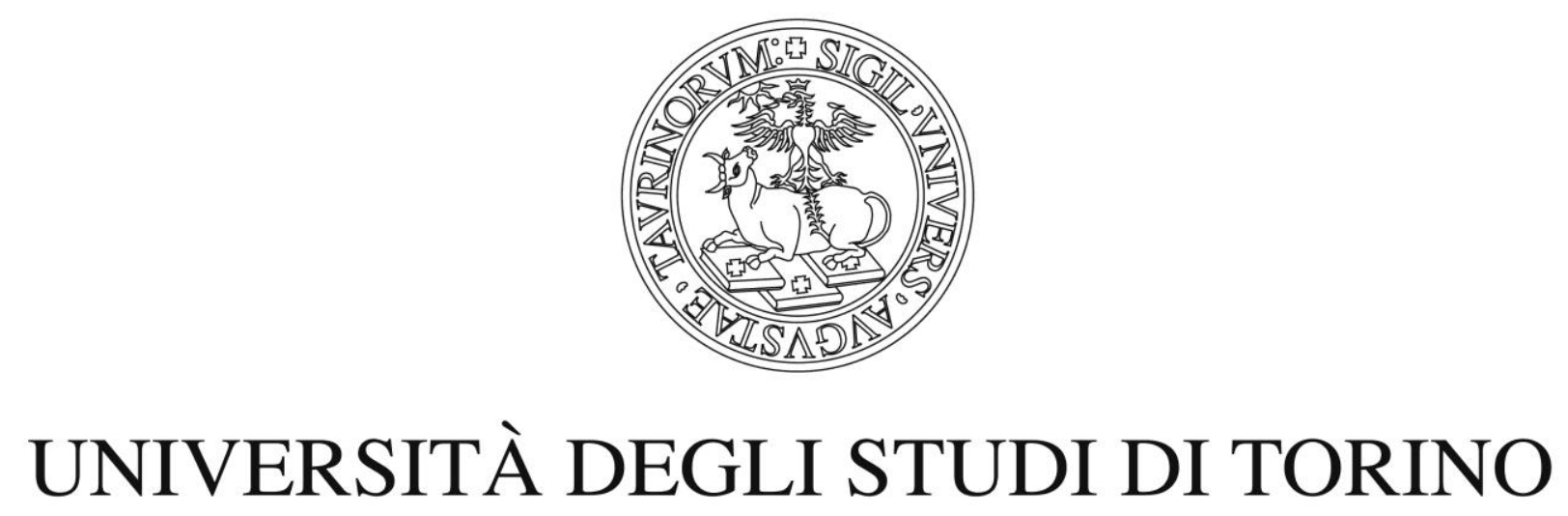

This is an author version of the contribution published on:

Journal of Feline Medicine and Surgery, 1-7, 2014 Mar 12. [Epub ahead of print] PMID:2462185

The definitive version is available at:

http://jfm.sagepub.com/content/early/2014/03/10/1098612X14527103.full.pdf+html

Questa è la versione dell'autore dell'opera:

Genetic and phenotypic characterisation of Escherichia coli producing cefotaximase-type extended-spectrum $\beta$ lactamases: first evidence of the ST131 clone in cats with urinary infections in Italy. Journal of Feline Medicine and Surgery, Marzo 12, 2014. [Epub ahead of print] PMID:2462185

La versione definitiva è disponibile alla URL: http://jfm.sagepub.com/content/early/2014/03/10/1098612X14527103.full.pdf+html 


\title{
Genetic and phenotypic characterisation of Escherichia coli producing cefotaximase-type extended- spectrum $\beta$-lactamases: first evidence of the ST131 clone in cats with urinary infections in Italy
}

\author{
Patrizia Nebbia $^{l}$, Clara Tramuta ${ }^{l}$, Rosangela Odore ${ }^{l}$ Daniele Nucera $^{2}$, Renato Zanatta ${ }^{l}$ and Patrizia Robino $^{l}$ \\ ${ }^{I}$ Department of Veterinary Sciences, University of Turin, Grugliasco, Turin, Italy; ${ }^{2}$ Department of \\ Agricultural, Forestry and Food Sciences, University of Turin, Grugliasco, Turin, Italy.
}

\begin{abstract}
The incidence of cefotaximase (CTX-M)-type extended-spectrum $\beta$-lactamase (ESBL)-producing Escherichia coli has increased dramatically in humans and animals since the middle of the last century. Escherichia coli that produce CTX-M $\beta$-lactamase represent a major cause of urinary tract infections, and pose a significant therapeutic challenge to both human and veterinary medicine. As data on uropathogenic CTX-M-producing strains in cats are limited, the aim of this study was to describe the genetic character and antibiotic resistance phenotypes of CTX-M-producing E. coli isolated from cats with cystitis. Seven of $15 \mathrm{E}$. coli bacteria isolated from 138 urine samples had the $C T X-M$ gene and were therefore included in this study. These isolates were screened by polymerase chain reaction for the presence of 14 extra-intestinal virulence factors, class 1 and class 2 integrons, and to identify their phylogenetic groups. Multi-locus sequence typing (MLST) of the strains and susceptibility testing (disc diffusion method) were also performed. Virulence factor iutA was the most frequent determinant identified (86.7\%), and the majority of CTX-M-producing strains $(n=5)$ carried class 1 integrons. MLST allowed us to discriminate four known sequence types (ST131, ST555, ST602, ST155) and three novel sequence types (ST3847, ST3848, ST4181). To the best of our knowledge, this is the first study to report uropathogenic CTX-M-producing E. coli ST131 in cats in Italy. Accurate diagnostics and prudent use of antimicrobials are recommended to avoid the spread of multidrug-resistant pathogens in veterinary medicine and to prevent their transmission to humans.
\end{abstract}

\section{Introduction}

Escherichia coli is an Enterobacteriaceae commonly found in the gastrointestinal tract of mammals; however, certain strains can cause a wide spectrum of intestinal and extra-intestinal diseases in humans and animals, including cats. ${ }^{1,4}$ In particular, $E$. coli has been identified as the most frequent pathogen in cat urinary tract infections (UTIs). ${ }^{5}$ The strains that cause UTIs, known as uropathogenic E. coli (UPEC), are characterised by specialised virulence factors, which are usually encoded on pathogenicity-associated islands (PAIs), genomic regions that may participate in the horizontal transfer of virulence genes. ${ }^{6}$ Recently, the role of pathogenic E. coli in severe extraintestinal infections, included UTIs, has been the subject of much research attention because of its importance from a veterinary clinical perspective and its zoonotic potential. ${ }^{6,7}$ Of particular concern is the increasing presence of extended-spectrum $\beta$-lactamase (ESBL)-producing E. coli; of these, the cefotaximase (CTX-M) family is the most prevalent type worldwide. ${ }^{8}$ CTX-M-encoding genes are located commonly on transferable elements (integrons, transposons, insertion sequences) carried by plasmids that facilitate the fast spread of resistance. ${ }^{9}$ Besides the spread through mobile genetic elements, CTX-M dissemination can also be due to epidemic clones associated with specific enzymes, such as CTX-M-15, which is responsible for nosocomial infections and contributes to the current pandemic CTX-M scenario. ${ }^{10}$ In particular, a clone of CTX-M-15-producing E. coli, named ST131, was identified recently. This clone belongs to a highly virulent phylogenetic group and harbours multidrug-resistant (MDR) plasmids, resulting in ST131 becoming a pathogen of significant clinical concern; indeed, a high incidence of both community-onset and hospital-acquired infections has been reported. ${ }^{11}$ The aim of this study was to investigate the occurrence of CTX-M-producing E. coli obtained from cat urine, and to characterise its genotypic and phenotypic features in order to assess the epidemiological characteristics of these strains in the study area.

\section{Materials and methods}

Sample collection and CTX-M-producing E. coli identification

Between February and December 2012, urine samples were collected, by cystocentesis, from 138 cats with uncomplicated cystitis. Feline patients and/or urine samples were referred to the Teaching Hospital of the Department of Veterinary Sciences of the University of Turin. Urine samples were cultured on MacConkey 
agar (Oxoid) and incubated overnight at $37^{\circ} \mathrm{C}$. Lactose-fermenting, indole-positive colonies were evaluated using the BBL Crystal test (Becton Dickinson), which allowed the identification of $15 \mathrm{E}$. coli bacteria. All urinary isolates were assumed to be uropathogenic, as they were associated with UTI. ${ }^{12}$ The bacterial genomic DNA of each isolate was extracted using a commercially available kit (InstaGene DNA; BioRad), according to the manufacturer's instructions, and tested for the $C T X-M$ gene by polymerase chain reaction (PCR) using the primers and conditions described in Table I. ${ }^{13}$ Of the $15 \mathrm{E}$. coli isolates identified, seven were CTX-M-positive; these strains were stored in Luria-Bertani broth (Oxoid) containing $15 \%$ glycerol at $-80^{\circ} \mathrm{C}$ until further use. The eight isolates confirmed not to be producers of CTX-M $\beta$-lactamases were excluded from the study. Detection of resistance genes and integrons All CTX-M-positive amplicons were sequenced and analysed using a BLAST search (http://blast.ncbi.nlm.nih. gov) in order to identify the type of CTX-M. The CTX-M-type ESBL-producing strains were then tested by PCR to investigate the presence of other $\beta$-lactamase genes: CMY-2, TEM and $S H V$ (primer sequences and amplification conditions are reported in Table I). ${ }^{13,14}$ Amplicons positive for TEM and SHV were sequenced and analysed to identify the variants. Class 1 and class 2 integrons were detected by PCR using primers targeting the Intl and Int2 genes, respectively. Variable regions were amplified and sequenced to identify gene cassettes. ${ }^{15}$

\section{Multi-locus sequence typing}

Multi-locus sequence typing (MLST) was carried out; the detailed protocol, including allelic type and sequence type (ST) assignment methods, is available from the MLST Databases at the Environmental Research Institute, University College Cork (http://mlst.ucc.ie/ mlst/dbs/Ecoli).

\section{Detection of extra-intestinal virulence genes and phylogenetic group}

Each E. coli isolate was screened by PCR for the presence of a range of virulence factors (VFs) associated with extraintestinal pathogenic E. coli (ExPEC) (Table I). ${ }^{16,22}$ The distribution of isolates across phylogenetic groups (A, $\mathrm{B} 1, \mathrm{~B} 2$ and $\mathrm{D})$ was determined by triplex PCR. ${ }^{23}$

\section{Antimicrobial susceptibility testing}

Suseptibility testing was carried out by the disc diffusion method according to the European Committee on Antimicrobial Susceptibility Testing (EUCAST) criteria guidelines (http://www.EUCAST.org). The following antibiotics (Neo-sensitabs; Rosco) were used: amikacin, $30 \mathrm{pg}$; amoxicillin clavulanate, $30 \mathrm{pg}$; ceftriaxone, 30 pg; cefepime, 30 pg; chloramphenicol, 30 pg; enrofloxacin, 10 pg; gentamicin, 10 pg; imipenem, $10 \mathrm{pg}$; nalidixan, $30 \mathrm{pg}$; nitrofurantoin, $100 \mathrm{pg}$; piperacillin, $100 \mathrm{pg}$; spectinomy-cin, $200 \mathrm{pg}$; streptomycin, 10 pg; sulphonamide, $240 \mathrm{pg}$; tetracycline, $30 \mathrm{pg}$; and trimethoprim, 5 /ig. Results of the antimicrobial susceptibility testing were interpreted according to the EUCAST guidelines on veterinary or human pathogens (the latter guidelines were used for tetracycline, nalidixan and cefepime). Strains resistant to at least three classes of antibiotics (including extended-spectrum cephalosporins, aminoglycosides, carbapenems, quinolones, sulphonamides and trimethoprim) were defined as MDR.

\section{Results}

The genetic character of the CTX-M-producing isolates detected in this study are reported in Table 2. The following variants were identified: CTX-M-14 $(n=5)$, CTX-M-1 $(n=1)$, and CTX-M-15 $(n=1)$. Two strains also contained TEM-1 and CMY-2 $\beta$-lactamases.

Four isolates were identified as known STs present in the MLST database: ST131, ST555 (clonal complex 538), ST602 (clonal complex 446) and ST155 (clonal complex 155). Three were novel STs (ST3847, ST3848 and ST4181) not yet assigned to a clonal complex. VF screening revealed the presence of $\mathrm{fimA}, \mathrm{hh} / \mathrm{A}$, cnfl, iutA and $f y u A$, typical virulence determinants of UPECs. The iut gene was common in 6/7 strains, and was always associated with other VFs. Moreover, the presence of some virulence genes, such as $h \mathrm{~h} / \mathrm{A}$, cnfl, fimA, fyuA and malX, suggests the presence of PAIs ${ }^{24},{ }^{26}$ in all E. coli strains tested, except in one isolate (cat 3).

Five CTX-M-type E. coli strains contained class 1 inte-grons; however, the gene cassettes aadA and $d f r A l+a a d A$ (conferring resistance to trimethoprim and streptomy-cin-spectinomycin, respectively) were found in only two isolates. All the class 1 integron-positive isolates were nalidixic acid-resistant, and one isolate contained class 2 integrons.

With regard to antibiotic susceptibility (Table 3), all strains exhibited an MDR phenotype. The CTX-Mproducing isolates were resistant to several $\beta$-lactam antibiotics. Moreover, all were susceptible to imipenem and three to amoxicillin clavulanate.

\section{Discussion}

This study shows that almost half of the E. coli bacteria isolated from cats with UTI were MDR, CTX-Mproducing strains. As expected, all CTX-M-positive strains possessed several VFs linked to the pathogenicity of ExPEC, including papC, $s f a, f y u A$ and $h h / A$, putative contributors of urovirulence.

Besides CTX-M genes, we identified TEM- 1 and $C M Y-2$ genes in two strains. This finding confirms that ESBL- 
producing E. coli strains may carry more than one $\beta$-lactamase gene. ${ }^{27}$ The majority of CTX-M-producing strains had class 1 integrons, suggesting the frequent presence of these integrons in ESBL-producing strains, and that they may influence the level of antibiotic resistance. The aacA7 cassette gene (responsible for resistance to amikacin) was absent in all samples, including the amikacin-resistant isolate, suggesting the existence of other resistance mechanisms of inactivation of aminoglycosides. ${ }^{28} C T X-M-14$ was the most common ESBL resistance gene found. Only one strain (cat 6) contained the $C T X-M-15$ gene, and this strain belonged to ST131, presenting the typical characteristics of this sequence type, such as the presence of $f y u A$, iutA, kpsMII and malX, and allocation to the B2 phylogroup. ${ }^{29}$

Over the last decade, the ST131 virulent pandemic clone has emerged in hospitals and in the community worldwide, causing outbreaks of MDR infections across the globe. ${ }^{30}$ It has been frequently described as a urinary pathogen in humans, ${ }^{31}$ and a fatal case of urosepsis associated with a multi-resistant strain of E. coli ST131 was reported recently ${ }^{30}$ Although rarely isolated from companion animals, a recent report found E. coli ST131 to distribute among human and animal household members in Australia, suggesting serious clinical and public health implications. ${ }^{32}$ In Europe, until now, ST131 has only been isolated from dogs, horses, ${ }^{33}$ poultry $^{34}$ and pigs ${ }^{35}$. Huber et $\mathrm{al}^{3}$ identified uropathogenic CTX-M-15 E. coli in dogs and cats; however, they did not find any ST131 clones in their study. Therefore, to the best of our knowledge, this is the first report of uropathogenic CTX-M-producing E. coli ST131 in cats in Italy.

We also detected the presence of ST155, recently isolated in E. coli carrying CTX-M-1 from Austrian cats ${ }^{36}$ and Swedish broilers, ${ }^{37}$ and ST602, recently identified in CTX-M-14 isolates from avian species in Italy ${ }^{38}$ and from Swedish broilers. ${ }^{37}$ Interestingly, the fourth ST identified (ST555) has been reported in E. coli isolated from patients with asymptomatic bacteriuria. ${ }^{39}$ In our study, a high rate of quinolone resistance was observed. This finding can be ascribed to the fact that plasmids carrying the $C T X-M$ genes often harbour resistance genes for other antibiotic classes, such as fluoroquinolones and aminoglycosides. ${ }^{40}$ Indeed, as expected, the ST131 strain in our study was fluoroquinolone-resistant. Three strains were susceptible to amoxicillin clavulanate. However, despite the fact that ESBL-producing strains may appear susceptible to a penicillin/ $\beta$-lactamase inhibitor combination and cephalosporins in vitro, the clinical use of these drugs remains controversial and should be approached with caution. From a clinical point of view, our results recommend the prudent use of antimicrobials in cats affected by UTIs as the emergence of resistant uropathogens is likely to negatively affect the effectiveness of empiric therapy. The antimicrobial agents most commonly used to treat feline uncomplicated UTIs include $\beta$-lactams, fluoroquinolones and the drug combination trimethoprim plus sulfamethoxazole. However, according to our results, these drugs should not be used as first-line drug therapy unless susceptibility testing is performed. Moreover, owing to the risk of blindness, the clinical use of fluoroquinolones for feline UTIs should be limited. ${ }^{41}$ The administration of last-line antimicrobials from human medicine for veterinary purposes should also be discouraged or avoided despite the demonstrated efficacy of imipenem in the treatment of antimicrobial resistant infections in cats. ${ }^{42,43}$ In contrast, although the use of nitrofurantoin in cats presents some disadvantages, such as high toxicity and poor pharmacokinetic characteristics, this drug should be considered as a therapeutic option for urinary infections caused by ESBL-producing E. coli. ${ }^{44}$ However, as nitrofurantoin is not licensed for animal use in Italy, the rationale for its off-label administration could be justified on the basis of its benefit/risk ratio. This should be complemented with a pharma-covigilance report concerning the lack of efficacy of first-line authorised antimicrobials. Feline lower urinary tract diseases are seldom caused by bacteria, but more often by obstructive idiopathic cystitis, urethral plugs or urinary calculi. ${ }^{5,45}$ Nevertheless, in many instances these conditions are treated with antimicrobials, thus promoting the selection of resistant strains. It is therefore recommended that the necessary diagnostics are performed before starting antimicrobial therapy for feline UTIs. At the very least, initial antimicrobial selection should be based on urine sediment examination to identify the presence of bacteria and on urine $\mathrm{pH}^{41}$

\section{Conclusions}

This study is the first to report the presence of the uropathogenic E. coli ST131 isolate producing CTX-M-15 in cats in Italy. Considering that pets and owners share extra-intestinal E. coli, basic hygiene measures and infection control strategies should be implemented, especially in veterinary clinics and teaching hospitals, in order to prevent the diffusion of this microorganism. Finally, the prudent use of antimicrobials and accurate diagnostic procedures should be emphasised to avoid the further spread of MDR pathogens in veterinary medicine. 
Table 1. PCR primers used in the study to detect $\beta$-lactamase and extra-intestinal virulence factor genes.

\begin{tabular}{|c|c|c|c|c|}
\hline $\begin{array}{c}\text { Target } \\
\text { gene }\end{array}$ & Primer sequence (5' to $\left.3^{\prime}\right)$ & $\begin{array}{l}\text { Product size } \\
\text { (bp) }\end{array}$ & $\begin{array}{l}\text { Annealing } \\
\text { temp }\left({ }^{\circ} \mathbf{C}\right)\end{array}$ & Reference \\
\hline CTX-M & $\begin{array}{l}\text { ATGTGCAGYACCCAGTAARGTKATGGC } \\
\text { TGGGTRAARTARGTSACCAGAAYCAGCGG }\end{array}$ & 593 & 60 & \multirow[b]{2}{*}{ (13) } \\
\hline$C M Y-2$ & $\begin{array}{l}\text { GCACTTAGCCACCTATACGGCAG } \\
\text { GCTTTTCAAGAATGCGCCAGG }\end{array}$ & 758 & 58 & \\
\hline TEM & $\begin{array}{l}\text { ATAAAATTCTTGAAGAC } \\
\text { TTACCAATGCTTAATCA }\end{array}$ & 1075 & 45 & \multirow[b]{2}{*}{ (14) } \\
\hline SHV & $\begin{array}{l}\text { TGGTTATGCGTTATATTCGCC } \\
\text { GCTTAGCGTTGCCAGTGCT }\end{array}$ & 867 & 50 & \\
\hline afa & $\begin{array}{l}\text { GCTGGGCAGCAAACTGATAACTCTC } \\
\text { CATCAAGCTGTTTTGTTCGTCCGCCG }\end{array}$ & 750 & 65 & \multirow{3}{*}{ (16) } \\
\hline papC & $\begin{array}{l}\text { GACGGCTGTACTGCAGGGTGTGGCG } \\
\text { ATATCCTTTCTGCAGGGATGCAATA }\end{array}$ & 328 & 61 & \\
\hline$s f a$ & $\begin{array}{l}\text { CTCCGGAGAACTGGGTGCATCTTAC } \\
\text { CGGAGGAGTAATTACAAACCTGGCA }\end{array}$ & 410 & 64 & \\
\hline fimA & $\begin{array}{l}\text { CGGCTCTGTCCCTSAGT } \\
\text { GTCGCATCCGCATTAGC }\end{array}$ & 500 & 52 & \multirow[b]{2}{*}{ (17) } \\
\hline iutA & $\begin{array}{l}\text { ATGAGCATATCTCCGGACG } \\
\text { CAGGTCGAAGAACATCTGG }\end{array}$ & 587 & 58 & \\
\hline \multirow{2}{*}{$c d t$} & $\begin{array}{l}\text { GAAAGTAAATGGAATATAAATGTCCG } \\
\text { AAATCACCAAGAATCATCCAGTTA }\end{array}$ & 466 & 55 & \multirow{2}{*}{ (18) } \\
\hline & $\begin{array}{l}\text { GAAAATAAATGGAACACACATGTCCG } \\
\text { AAATCTCCTGCAATCATCCAGTTA }\end{array}$ & 466 & 55 & \\
\hline cnfl & $\begin{array}{l}\text { GGCGACAAATGCAGTATTGCTTGG } \\
\text { GACGTTGGTTGCGGTAATTTTGGG }\end{array}$ & 522 & 60 & (19) \\
\hline hlyA & $\begin{array}{l}\text { AACAAGGATAAGCACTGTTCTGGCT } \\
\text { ACCATATAAGCGGTCATTCCCGTCA }\end{array}$ & 1177 & 62 & (20) \\
\hline fyuA & $\begin{array}{l}\text { TGATTAACCCCGCGACGGGAA } \\
\text { CGCAGTAGGCACGATGTTGTA }\end{array}$ & 880 & 63 & \multirow{4}{*}{ (21) } \\
\hline malX & $\begin{array}{l}\text { GGACATCCTGTTACAGCGCGCA } \\
\text { TCGCCACCAATCACAGCCGAAC }\end{array}$ & 930 & 63 & \\
\hline $\operatorname{traT}$ & $\begin{array}{l}\text { GGTGTCGTGCGATGAGCACAG } \\
\text { CACGGTTCAGCCATCCCTGAG }\end{array}$ & 290 & 63 & \\
\hline kpsMII & $\begin{array}{l}\text { GCGCATTTGCTGATACTGTTG } \\
\text { CATCCAGACGATAAGCATGAGCA }\end{array}$ & 272 & 63 & \\
\hline$c l b B$ & $\begin{array}{l}\text { GATTTGGATACTGGCGATAACCG } \\
\text { CCATTTCCCGTTTGAGCACAC }\end{array}$ & 579 & 55 & \multirow[t]{2}{*}{ (22) } \\
\hline hra & $\begin{array}{l}\text { CGAATCGTTGTCACGTTCAG } \\
\text { TATTTATCGCCCCACTCGTC }\end{array}$ & 162 & 55 & \\
\hline
\end{tabular}




\begin{tabular}{|c|c|c|c|c|c|c|}
\hline Strain & PG & ST & Type of ESBL & Integrons & $\begin{array}{c}\text { Gene } \\
\text { cassettes }\end{array}$ & Virulence Factors \\
\hline Cat 1 & B2 & 555 & CTX-M-14 & - & - & clbB, cnfl, fimA, hlyA kps $M I I$ papC sfa, traT \\
\hline Cat 2 & B2 & $4181 *$ & CTX-M-14 & - & - & clbB iutA, fims fius kps MIL malX, sfa \\
\hline Cat 3 & B2 & 155 & CTX-M-1 & Class 1 & - & fims iutA \\
\hline Cat 4 & B1 & 602 & CTX-M-14 & Class 1 & - & fims furs, iuts, traT \\
\hline Cat 5 & A & $3848^{*}$ & CTX-M-14 + CMY-2 & Class 1 & aadAI & iuts, malX traT \\
\hline Cat 6 & $\mathrm{~B} 2$ & 131 & CTX-M-15 & Class 1 & - & fuus hro, iuts kps MI, malx traT \\
\hline Cat 7 & A & $3847^{*}$ & CTX-M-14 + CMY-2+TEM-1 & $\begin{array}{l}\text { Class } 1 \\
\text { Class } 2\end{array}$ & $\begin{array}{l}d f r A I+a a d A I \\
-\end{array}$ & fous iutA, malX, trat \\
\hline
\end{tabular}

$3 \quad \mathrm{PG}=$ phylogenetic group, $\mathrm{ST}=$ sequence type, $*$ new MLST type

1 Table 3. Antibiotic susceptibility pattems of $7 \mathrm{E}$. coli producing CTX-M isolated from urine samples of 2 cats.

$\$$

\begin{tabular}{|c|c|c|c|c|c|c|c|c|c|c|c|c|c|c|c|c|}
\hline Strain & PIPRA & AMC & CTR & FEP & IPM & AMI & CLR & ENROF & GEN & NAL & NI & SPECT & STR & SULFA & TET & TRIM \\
\hline Cat 1 & $\mathrm{R}$ & $\mathrm{R}$ & $\mathrm{R}$ & $\mathrm{R}$ & $\mathrm{S}$ & $\mathrm{R}$ & $\mathrm{R}$ & $\mathrm{S}$ & $\mathrm{R}$ & $\mathrm{R}$ & $\mathrm{S}$ & $\mathrm{R}$ & $\mathrm{R}$ & $\mathrm{S}$ & $\mathrm{R}$ & $\mathrm{S}$ \\
\hline Cat 2 & $\mathrm{R}$ & $\mathrm{s}$ & $\mathrm{R}$ & $\mathrm{S}$ & S & S & S & S & $\mathrm{S}$ & $\mathrm{R}$ & $\mathrm{S}$ & $\mathrm{R}$ & I & $\mathrm{S}$ & S & S \\
\hline Cat 3 & $\mathrm{R}$ & $\mathrm{S}$ & $\mathrm{R}$ & $\mathrm{S}$ & $\mathrm{S}$ & $\mathrm{S}$ & $\mathrm{S}$ & $\mathrm{R}$ & $\mathrm{R}$ & $\mathrm{R}$ & $\mathrm{R}$ & $\mathrm{R}$ & I & $\mathrm{R}$ & $\mathrm{R}$ & $\mathrm{R}$ \\
\hline Cat 4 & $\mathrm{R}$ & $\mathrm{S}$ & $\mathrm{R}$ & $\mathrm{S}$ & $\mathrm{S}$ & $\mathrm{S}$ & $\mathrm{R}$ & $\mathrm{R}$ & $\mathrm{S}$ & $\mathrm{R}$ & $\mathrm{S}$ & $\mathrm{R}$ & I & $\mathrm{S}$ & $\mathrm{R}$ & $\mathrm{S}$ \\
\hline Cat 5 & $\mathrm{R}$ & I & $\mathrm{R}$ & $\mathrm{S}$ & $\mathrm{S}$ & $\mathrm{S}$ & S & $\mathrm{R}$ & $\mathrm{R}$ & I & $\mathrm{S}$ & $\mathrm{R}$ & $\mathrm{R}$ & $\mathrm{R}$ & $\mathrm{R}$ & $\mathrm{R}$ \\
\hline Cat 6 & $\mathrm{R}$ & I & $\mathrm{R}$ & I & S & $\mathrm{S}$ & S & $\mathrm{R}$ & $\mathrm{R}$ & $\mathrm{R}$ & $\mathrm{S}$ & $\mathrm{R}$ & I & $\mathrm{R}$ & $\mathrm{S}$ & $\mathrm{R}$ \\
\hline Cat 7 & $\mathrm{R}$ & $\mathrm{R}$ & $\mathrm{R}$ & $\mathrm{S}$ & $\mathrm{S}$ & $\mathrm{S}$ & $\mathrm{S}$ & $\mathrm{R}$ & $\mathrm{R}$ & $\mathrm{R}$ & $\mathrm{R}$ & $\mathrm{R}$ & $\mathrm{R}$ & $\mathrm{R}$ & $\mathrm{R}$ & $\mathrm{R}$ \\
\hline
\end{tabular}

$\mathrm{R}=$ resistance, $\mathrm{S}=$ susceptibility, $\mathrm{I}=$ intermediate susceptibility

PIPRA = piperacillin, $\mathrm{AMC}=$ amoxicillin-clavulanate, $\mathrm{CTR}=$ ceftriaxone, $\mathrm{FEP}=$ cefepime, $\mathrm{IPM}=$ imipenem; $\mathrm{AMI}=$ amikacin, $\mathrm{CLR}=$ chloramphenicol, $\mathrm{ENROF}=$ enrofloxacin, $\mathrm{GEN}=$ gentamicin, $\mathrm{NAL}=$ nalidixan, $\mathrm{NI}=$

7 nitrofurantoin, SPECT $=$ spectinomycin, STR $=$ streptomycin, SULFA = sulphonamide, TET = tetracyclin, TRIM

8 = trimethoprim 


\section{References}

1 Carattoli A, Lovari S, Franco A, et al. Extended-spectrum beta-lactamases in Escherichia coli isolated from dogs and cats in Rome, Italy, from 2001 to 2003. Antimicrob Agents Chemother 2005; 49: 833-835.

2 Harada K, Niina A, Nakai Y, et al. Prevalence of antimicrobial resistance in relation to virulence genes and phylo-genetic origins among urogenital Escherichia coli isolates from dogs and cats in Japan. Am J Vet Res 2012; 73:409-417.

3 Huber H, Zweifel C, Wittenbrink MM, et al. ESBL-producing uropathogenic Escherichia coli isolated from dogs and cats in Switzerland. Vet Microbiol 2013; 162: 992-996.

4 Ewers C, Grobbel M, Stamm I, et al. Emergence of human pandemic O25:H4-ST131 CTX-M-15 extended-spectrum-betalactamase-producing Escherichia coli among companion animals. / Antimicrob Chemother 2010; 65: 651-660.

5 White JD, Stevenson M, Malik R, et al. Urinary tract infections in cats with chronic kidney disease. Feline Med Surg2013; 15: $459-465$

6 Johnson JR, O'Bryan TT, Kuskowski M, et al. Ongoing horizontal and vertical transmission of virulence genes and papA alleles among Escherichia coli blood isolates from patients with diverse-source bacteremia. Infect Immun. 2001; 69: 5363-5374.

7 Belanger L, Garenaux A, Harel J, et al. Escherichia coli from animal reservoirs as a potential source of human extraintestinal pathogenic E. coli. Ferns Immunol Med Microbiol 2011; 62: 1-10.

8 Tamang MD, Nam HM, Gurung M, et al. Molecular characterization of CTX-M beta-lactamase and associated addiction systems in Escherichia coli circulating among cattle, farm workers, and the farm environment. Appl Environ Microbiol 2013; 79: 3898-3905.

Pitout JDD and Laupland KB. Extended-spectrum beta-lactamase-producing enterobacteriaceae: an emerging public-health concern. Lancet Infect Dis 2008; 8: 159-166.

10 Canton R and Coque TM. The CTX-M beta-lactamase pandemic. Curr Opin Microbiol 2006; 9: 466-475.

11 Peirano $\mathrm{G}$ and Pitout JDD. Molecular epidemiology of Escherichia coli producing CTX-M beta-lactamases: the worldwide emergence of clone ST131 O25:H4. hit J Antimicrob Agents 2010; 35: 316-321.

12 Bahrani-Mougeot NWGI, Donnemberg MS and Mobley HLT. Uropathogenic Escherichia coli. In: Donnenberg MS (ed). Escherichia coli. Virulence mechanisms of a versatile pathogen. San Diego: Academic Press, 2002, pp 239-268.

13 Hasman H, Mevius D, Veldman K, et al. beta-Lactamases among extended-spectrum beta-lactamase (ESBL)-resistant Salmonella from poultry, poultry products and human patients in The Netherlands. / Antimicrob Chemother 2005; 56: 115-121.

14 Jiang XF, Ni YX, Jiang YQ, et al. Outbreak of infection caused by Enterobacter cloacae producing the novel VEB-3 beta-lactamase in China. / Clin Microbiol 2005; 43: 826-831.

15 Nebbia P, Tramuta C, Giammarino M, et al. Antimicrobial resistance, class 1 and 2 integrons and gene cassettes in avian Escherichia coli. ltd J Anim Sci 2008; 7: 391-395.

16 Le Bouguenec C, Archambaud M and Labigne A. Rapid and specific detection of the pap, afa, and sfa adhesin-encoding operons in uropathogenic Escherichia coli strains by polymerase chain reaction. / Clin Microbiol 1992; 30: 1189-1193.

17 Moulin-Schouleur M, Schouler C, Tailliez P, et al. Common virulence factors and genetic relationships between O18:K1:H7 Escherichia coli isolates of human and avian origin. / Clin Microbiol 2006; 44: 3484-3492.

18 Toth I, Herault F, Beutin L, et al. Production of cytolethal distending toxins by pathogenic Escherichia coli strains isolated from human and animal sources: Establishment of the existence of a new cdt variant (type IV). / Clin Micro biol 2003; 41: 4285-4291.

19 Pass MA, Odedra R and Batt RM. Multiplex PCRs for identification of Escherichia coli virulence genes. / Clin Microbiol 2000; 38: 2001-2004.

20 Yamamoto S, Terai A, Yuri K, et al. Detection of urovir-ulence factors in Escherichia coli by multiplex polymerase chain reaction. FEMS Immunol Med Microbiol1995; 12: 85-90.

21 Johnson JR and Stell AL. Extended virulence genotypes of Escherichia coli strains from patients with urosepsis in relation to phylogeny and host compromise. / Infect Dis 2000; 181: 261-272.

22 Johnson JR, Johnston B, Kuskowski MA, et al. Molecular epidemiology and phylogenetic distribution of the Escherichia coli pks genomic island. / Clin Microbiol 2008; 46: 3906-3911.

23 Clermont O, Bonacorsi S and Bingen E. Rapid and simple determination of the Escherichia coli phylogenetic group. Appl Environ Microbiol 2000; 66: 4555-4558.

24 Ostblom A, Adlerberth I, Wold AE, et al. Pathogenicity island markers, virulence determinants malX and usp, and the capacity of Escherichia coli to persist in infants' commensal microbiotas. Appl Environ Microbiol 2011; 77: 2303-2308.

25 Soto SM, Jimenez de Anta MT and Vila J. Quinolones induce partial or total loss of pathogenicity islands in uropathogenic Escherichia coli by SOS-dependent or -independent pathways, respectively. Antimicrob Agents Chemother 2006; 50: 649-653.

26 Johnson JR, Kuskowski MA, Gajewski A, et al. Extended virulence genotypes and phylogenetic background of Escherichia coli isolates from patients with cystitis, pyelo nephritis, or prostatitis. J Infect Dis 2005; 191: 46-50.

27 Woodford N, Carattoli A, Karisik E, et al. Complete nucleotide sequences of plasmids pEK204, pEK499, and pEK516, encoding CTX-M enzymes in three major Escherichia coli lineages from the United Kingdom, all belonging to the international O25:H4ST131 clone. Antimicrob Agents Chemother 2009; 53: 4A72-A482.

28 Woegerbauer M, Zeinzinger J, Springer B, et al. Prevalence of the aminoglycoside phosphotransferase genes aph(3')-Illa and aph(3')-IIa in Escherichia coli, Enterococcus faecalis, Enterococcus faecium, Pseudomonas aeruginosa, Salmonella enterica subsp enterica, and Staphylococcus aureus isolates in Austria. ] Med Microbiol 2014; 63: 21-17. 
29 Olesen B, Hansen DS, Nilsson F, et al. Prevalence and characteristics of the epidemic multiresistant Escherichia coli ST131 clonal group among extended-spectrum beta-lactamase-producing E. coli isolates in Copenhagen, Den mark. / Clin Microbiol 2013; 51: 1779-1785.

30 Owens RC, Johnson JR, Stogsdill P, et al. Community transmission in the United States of a CTX-M-15-producing sequence type ST131 Escherichia coli strain resulting in death. / Clin Microbiol 2011; 49: 3406-3408.

31 Gibreel TM, Dodgson AR, Cheesbrough J, et al. Population structure, virulence potential and antibiotic susceptibility of uropathogenic Escherichia coli from Northwest England. J Antimicrob Chemother 2012; 67: 346-356.

32 Platell JL, Cobbold RN, Johnson JR, et al. Clonal group distribution of fluoroquinolone-resistant Escherichia coli among humans and companion animals in Australia. J Antimicrob Chemother 2010; 65: 1936-1938.

33 Dierikx CM, Van Duijkeren E, Schoormans AHW, et al. Occurrence and characteristics of extended-spectrumlactamase- and AmpC-producing clinical isolates derived from companion animals and horses. / Antimicrob Chemother 2012; 67: 1368-1374.

34 Mora A, Herrera A, Mamani R, et al. Recent emergence of clonal group O25b:K1:H4-B2-ST131 ibeA strains among Escherichia coli poultry isolates, including CTX-M-9-producing strains, and comparison with clinical human isolates. Appl Environ Microbiol 2010; 76: 6991-6997.

35 Cortes $\mathrm{P}$, Blanc V, Mora A, et al. Isolation and characterization of potentially pathogenic antimicrobial-resistant Escherichia coli strains from chicken and pig farms in Spain. Appl Environ Microbiol 2010; 76: 2799-2805.

36 Franiek N, Orth D, Grif K, et al. ESBL-producing E. coli and EHEC in dogs and cats in the Tyrol as possible source of human infection. BerlMunch Fierarztl Wochenschr 2012; 125: 469-475. (in German).

37 Borjesson S, Bengtsson B, Jernberg C, et al. Spread of extended-spectrum beta-lactamase producing Escherichia coli isolates in Swedish broilers mediated by an incl plasmid carrying bla (CTX-M-1). Acta Vet Scand 2013; 55: 3.

38 Giufre M, Graziani C, Accogli M, et al. Escherichia coli of human and avian origin: detection of clonal groups associated with fluoroquinolone and multidrug resistance in Italy. / Antimicrob Chemoth 2012; 67: 860-867.

39 Zdziarski J, Svanborg C, Wullt B, et al. Molecular basis of commensalism in the urinary tract: low virulence or virulence attenuation? Infect Immun 2008; 76: 695-703.

40 Wieler LH, Ewers C, Guenther S, et al. Methicillin-resistant staphylococci (MRS) and extended-spectrum betalactamases (ESBL)-producing Enterobacteriaceaein companion animals: Nosocomial infections as one reason for the rising prevalence of these potential zoonotic pathogens in clinical samples, hit \} Med Microbiol 2011; 301: 635641.

41 Barsanti JA. Genithourinary infections. In: Greene CE (ed). Infectious diseases of dog and cat. 3rd ed. Philadelphia: Saunders Elsevier, 2006, pp 935-961.

42 Albarellos GA, Denamiel GA, Montoya L, et al. Pharmacokinetics of imipenem after intravenous, intramuscular and subcutaneous administration to cats. / Feline Med Surg 2013; 15: 483-487.

43 Guardabassi L, Schwarz S and Lloyd DH. Pet animals as reservoirs of antimicrobial-resistant bacteria. \} Antimicrob Chemother 2004; 54: 321-332.

44 Maaland $\mathrm{M}$ and Guardabassi L. In vitro antimicrobial activity of nitrofurantoin against Escherichia coli and Staphylococcus pseudintermedius isolated from dogs and cats. Vet Microbiol 2011; 151: 396-399.

45 Gerber B, Boretti FS, Kley S, et al. Evaluation of clinical signs and causes of lower urinary tract disease in European cats. / Small Anim Pract 2005; 46: 571-577. 